\title{
ACADEMIC HELP SEEKING TERHADAP DOSEN PADA MAHASISWA FAKULTAS PSIKOLOGI UNIVERSITAS PADJADJARAN: PERAN FEAR OF FAILURE
}

\author{
Astri Nur Endah, Fitriani Yustikasari Lubis*, dan Whisnu Yudiana \\ Fakultas Psikologi, Universitas Padjadjaran \\ Jl. Raya Bandung Sumedang KM 21 Kabupaten Sumedang, Jawa Barat 45363 \\ E-mail : fitriani.y.lubis@unpad.ac.id
}

\begin{abstract}
ABSTRAK
Keberhasilan pembelajaran di perguruan tinggi menuntut keaktifan dari mahasiswa baik secara fisik, emosional, maupun mental. Meski demikian, mahasiswa tetap membutuhkan orang lain ketika mengalami kesulitan melaksanakan aktivitas akademik, misalnya dengan meminta bantuan dosen (academic help seeking). Penelitian ini bertujuan untuk mengetahui hubungan antara fear of failure dengan academic help seeking terhadap dosen. Penelitian ini menggunakan metode korelasional. Metode sampling yang digunakan adalah simple random sampling dengan sampel penelitian sebanyak 185 orang mahasiswa Fakultas Psikologi Universitas Padjadjaran tahun kedua dan ketiga. Alat ukur yang digunakan adalah Performance Failure Appraisal Inventory serta Computer Science Help Seeking Scales. Data dianalisis menggunakan korelasi Spearman. Hasil yang diperoleh menunjukkan bahwa fear of failure memiliki hubungan dengan academic help seeking pada tiga dimensi, yaitu instrumental help seeking, executive help seeking, dan avoidance help seeking. Tidak ditemukan hubungan antara fear of failure dengan perceived benefit of help seeking. Fear of failure menimbulkan dua kecenderungan pada mahasiswa, yakni kecenderungan meminta bantuan dan kecenderungan menghindari meminta bantuan kepada dosen.
\end{abstract}

Kata kunci: fear of failure; academic help seeking; mahasiswa.

\begin{abstract}
Educational accomplishment in higher education requires student to be involved physically, emotionally, and mentally. However, students still need other people when they have difficulty in doing academic activities, for example by asking for assistance from lecturers (academic help seeking). This research was conducted to determine the relationship between fear of failure and academic help seeking toward lecturers. This research used correlational method with simple random sampling which involved 185 second-and third-year Faculty of Psychology students of Universitas Padjadjaran. The research instruments that were used in this research included Performance Failure Appraisal Inventory and Computer Science Help Seeking Scales. The collected data was analyzed with Spearman's correlation. The result indicated that fear of failure had positive relationship with academic help seeking on three dimensions, which were instrumental help seeking, executive help seeking, and avoidance help seeking. There was no significant relationship between fear of failure and perceived benefit of help seeking. Fear of failure generated two tendencies in students, which were the tendency to ask for help and the tendency to avoid asking for help from lecturers.
\end{abstract}

Keywords: fear of failure; academic help seeking; undergraduate student. 


\section{PENDAHULUAN}

Perguruan tinggi adalah jenjang pendidikan lanjutan yang dapat ditempuh seseorang setelah lulus dari sekolah menengah atas. Seseorang yang menempuh pendidikan di perguruan tinggi bukan hanya mengalami perubahan status dari siswa menjadi mahasiswa, tetapi juga perubahan lain, salah satunya yaitu dalam hal metode pembelajaran. Menurut Kusumah (2009), metode pembelajaran pada jenjang pendidikan menengah lebih terpusat pada guru, artinya guru biasanya lebih aktif dalam menyampaikan materi pembelajaran dan siswa lebih sering menerima apa yang disampaikan guru. Sementara itu, di perguruan tinggi metode pembelajaran lebih terpusat pada mahasiswa, di mana mahasiswa dituntut untuk terlibat aktif dalam proses pembelajaran, dan dosen hanya berperan sebagai fasilitator yang memberikan arahan mengenai hal-hal yang harus dipelajari mahasiswa. Sejalan dengan hal tersebut, Abidin (2005) menyatakan bahwa keterlibatan mahasiswa dalam proses pembelajaran adalah salah satu kunci keberhasilan di perguruan tinggi.

Mahasiswa diharapkan untuk dapat melaksanakan proses pembelajaran secara mandiri. Meski demikian, mahasiswa tetap membutuhkan orang lain dalam melaksanakan beberapa aktivitas akademik, misalnya mengerjakan tugas kelompok dan memahami materi. Aktivitas akademik yang melibatkan bantuan orang lain dalam istilah psikologi disebut dengan academic help seeking. Academic help seeking merupakan perilaku meminta bantuan pada individu yang muncul ketika individu tersebut mengalami kesulitan namun termotivasi untuk meraih pencapaian tertentu dalam proses pembelajarannya (Pajares, Cheong, \& Oberman, 2004). Perilaku ini membantu mahasiswa menghadapi konsep-konsep kompleks yang mungkin tidak sepenuhnya dapat ia pahami sendiri, sehingga academic help seeking merupakan cara yang bisa digunakan mahasiswa untuk mendapatkan informasi agar dapat menyelesaikan masalah yang dialami dalam proses pembelajaran.

Menurut Järvelä (2011), jika mahasiswa memerlukan bantuan namun tidak mencarinya, performa mereka akan memburuk karena kehilangan kesempatan untuk mendapatkan informasi tambahan mengenai materi pembelajaran dari guru atau dosen melalui interaksi sosial dengan mereka. Academic help seeking yang tinggi akan memungkinkan mahasiswa terus belajar dan dapat meningkatkan prestasi akademiknya, sedangkan academic help seeking yang rendah akan menyebabkan kerugian bagi mahasiswa selama proses pembelajaran (Hidemasa; Zimmerman, \& Martinez dalam Syafitri, 2018).

Pentingnya academic help seeking dalam membantu proses pembelajaran ternyata tidak serta merta diaplikasikan mahasiswa di dalam kelas. Menurut Ryan, Pintrich, \& Midgley (2001), ditemukan bahwa banyak siswa yang tidak mencari bantuan ketika di kelas meskipun bantuan itu sedang diperlukan dan tersedia. Selain itu, terlepas dari kesadaran akan masalah yang dimiliki dan ketersediaan bantuan, banyak pula siswa yang berperilaku pasif tanpa pernah meminta bantuan (Newman, 2000).

Keengganan siswa untuk meminta bantuan di dalam kelas ini menurut Altermatt et al. (2002) disebabkan karena mereka lebih memilih untuk meminta bantuan kepada teman sebayanya secara langsung dibandingkan dengan mengajukan pertanyaan di kelas kepada dosen. Teman juga dianggap siswa sebagai sosok yang tidak mengancam diri, tidak akan menghakimi, serta memiliki ikatan emosional yang menjadikan mereka tidak sungkan untuk bertanya (Shim, Rubenstein, \& Drapeau, 2016). Lebih lanjut, Ryan \& Pintrich (1997) menyatakan bahwa banyak siswa yang khawatir akan mendapat penilaian negatif ketika meminta bantuan. Kekhawatiran yang dirasakan muncul karena kebutuhan akan bantuan mungkin dipersepsikan orang lain sebagai bukti bahwa siswa kurang memiliki kemampuan dan hal itu cenderung menimbulkan penilaian negatif dari orang lain (Butler, 1998; Ryan, Hicks, \& Midgley, 1997). Sejalan dengan hal tersebut, Shim, Rubenstein, \& Drapeau (2016) menyatakan bahwa academic help seeking pada dasarnya melibatkan psychological cost yang sering kali lebih besar dibandingkan dengan manfaat melakukannya. Artinya, anggapan bahwa meminta bantuan dapat mengungkap kelemahan atau ketidakmampuan siswa dalam menyelesaikan masalah secara mandiri akan mengalahkan upaya siswa tersebut untuk mencoba memahami materi atau mendapatkan jawaban yang tepat dari orang lain.

Rasa takut akan penilaian buruk ketika meminta bantuan dijelaskan lebih lanjut melalui konsep rasa malu atau shame yang merupakan komponen utama dari fear of failure. Menurut Murray (1938) dan Atkinson (1953) dalam Elliot \& Thrash (2004), fear of failure adalah kecenderungan disposisional yang berbasis penghindaran kegagalan karena seseorang merasa malu terhadap kegagalan. Fear of failure berhubungan dengan ancaman penilaian negatif terhadap kemampuan dan diri individu secara keseluruhan dalam melakukan performansi, sehingga konsekuensi kegagalan diyakini merupakan sumber yang ditakuti 
atau dicemaskan oleh individu, bukan kegagalan itu sendiri (Mc Clelland (1953) dalam Nainggolan, 2007). Hal ini juga didukung oleh Conroy, Willow, \& Metzler (2002) yang menyatakan bahwa fear of failure adalah dorongan untuk menghindari kegagalan, terutama konsekuensi negatif kegagalan berupa rasa malu, menurunnya konsep diri individu, dan hilangnya pengaruh sosial.

Fear of failure adalah salah satu komponen dalam teori Achievement Motivation yang dijelaskan oleh Atkinson (1957). Menurut Atkinson (1957), achievement motivation terdiri dari dua komponen, di antaranya motive for success, yaitu kecenderungan dan dorongan yang dimiliki individu untuk meraih keberhasilan, dan motive to avoid failure atau fear of failure, yaitu kecenderungan dan dorongan yang dimiliki individu untuk menghindari suatu aktivitas berprestasi karena merasa takut akan pengaruh negatif kegagalan. Fear of failure muncul sebagai hasil ketidakmampuan siswa menghadapi tuntutan akademis yang diperoleh. Sebagai akibat dari ketidakmampuan tersebut, siswa pun dapat melakukan tindakan defensif atau pertahanan diri (Freud dalam Atkinson, 1993).

Dari kedua komponen achievement motivation yang dijelaskan sebelumnya, penelitian ini hanya berfokus pada konsep fear of failure karena berkaitan dengan fenomena yang ditemukan, yakni banyaknya mahasiswa yang enggan bertanya kepada dosen di kelas karena takut pertanyaan mereka dinilai buruk. Dalam kaitannya dengan academic help seeking, mahasiswa yang takut akan konsekuensi kegagalan memiliki kemungkinan untuk cenderung menghindari meminta bantuan dosen sekalipun mereka sedang mengalami kesulitan akademik.

Penelitian sebelumnya mengenai fear of failure banyak dilakukan dalam setting akademik. Beberapa aspek akademik yang ditelaah terhadap fear of failure di antaranya, prokrastinasi (Fatimah et al., 2011), school engagement (Caraway et al., 2003), perfeksionisme (Conroy, Kaye, \& Fifer, 2007), achievement goal (Hung et al., 2009), dan persepsi terhadap harapan orang tua (Nainggolan, 2007). Sementara itu, penelitian yang menguji hubungan antara fear of failure dengan academic help seeking masih dapat dilakukan eksplorasi lebih lanjut. Dalam penelitian ini akan dikaji hubungan antara fear of failure dan academic help seeking, khususnya pada dosen yang dihipotesiskan memiliki karakteristik khusus. Hal ini bertujuan agar mahasiswa dapat memahami faktor-faktor dari fear of failure yang berkaitan dengan kecenderungan seseorang dalam melakukan academic help seeking, sehingga mereka tidak ragu lagi dalam melakukan academic help seeking terhadap dosen di kemudian hari.

\section{METODE}

Penelitian ini dilakukan menggunakan rancangan noneksperimental dengan metode korelasional, yaitu suatu metode yang digunakan untuk mengukur hubungan dua variabel yang diteliti dan kemudian menentukan derajat hubungan yang ada di antara kedua variabel tersebut (Christensen, 2007). Teknik sampling yang digunakan adalah simple random sampling. Populasi penelitian merupakan mahasiswa Fakultas Psikologi Universitas Padjadjaran tahun kedua dan ketiga yang masih aktif melakukan kegiatan perkuliahan dan memiliki beban mata kuliah tatap muka di kelas. Sebanyak 185 mahasiswa diambil sebagai sampel dari total 463 mahasiswa. Data demografi penelitian ini dapat dilihat pada Tabel 4.

Tabel 4. Data Demografi

\begin{tabular}{ccc}
\hline Demografis & Frekuensi & Persentase (\%) \\
\hline Jenis Kelamin & & \\
Laki - laki & 41 & 22,2 \\
Perempuan & 144 & 77,8 \\
\hline Tahun & & \\
Ketiga & 89 & 48,1 \\
Kedua & 96 & 51,9 \\
\hline
\end{tabular}

Alat ukur yang digunakan pada penelitian ini terdiri dari dua alat ukur. Fear of failure diukur menggunakan Performance Failure Appraisal Inventory (PFAI) yang dikembangkan oleh Conroy, Willow, $\&$ Metzler (2002). Alat ukur ini terdiri dari 25 item dan memiliki lima dimensi, yang diterjemahkan ke dalam Bahasa Indonesia melalui metode forward-backward translation. PFAI dapat mengukur fear of 
failure secara umum, di mana item-item-nya merupakan item gabungan dari kelima dimensi fear offailure. Skala yang digunakan pada alat ukur ini adalah skala Likert dari 1 hingga $5(1=$ sangat tidak sesuai; $2=$ tidak sesuai; $3=$ netral; 4 = sesuai; $5=$ sangat sesuai). Reliabilitas PFAI yaitu 0,795 untuk general fear of failure, 0,856 untuk dimensi fear of experiencing shame and embarrassment, 0,770 untuk dimensi fear of devaluing one's self-estimate, 0,713 untuk dimensi fear of having an uncertain future, 0,864 untuk dimensi fear of important others losing interest, dan 0,858 untuk dimensi fear of upsetting important others. Berdasarkan kriteria Kaplan \& Saccuzo (2005), alat ukur ini dapat diandalkan. Validitas PFAI diperoleh melalui uji confirmatory factor analysis (CFA). Bukti validitas PFAI disajikan pada Tabel 1.

Tabel 1. Validitas Alat Ukur Performance Failure Appraisal Inventory

\begin{tabular}{cccc}
\hline Dimensi & $\begin{array}{c}\text { RMSEA } \\
<0,08 \text { (Schumacker } \\
\text { \& Lomax, 2004) }\end{array}$ & $\begin{array}{c}\text { SRMR } \\
<0,08(\mathrm{Hu} \& \\
\text { Bentler, 1999) }\end{array}$ & $\begin{array}{c}\text { CFI } \\
>0,95(\mathrm{Hu} \& \\
\text { Bentler, 1999) }\end{array}$ \\
\hline GFOF & 0,000 & 0,021 & 1,000 \\
FESH & 0,069 & 0,037 & 0,990 \\
FDOS & 0,000 & 0,012 & 1,000 \\
FHUF & 0,042 & 0,023 & 1,000 \\
FIOLS & 0,000 & 0,037 & 1,000 \\
FUIO & 0,099 & 0,030 & 0,990 \\
\hline
\end{tabular}

Keterangan: $\mathrm{GFOF}=$ General fear of failure; $\mathrm{FESH}=$ Fear of experiencing shame and embarrassment; FDOS = Fear of devaluing one's self-estimate; FHUF $=$ Fear of having an uncertain future; FIOLS = Fear of important others losing Interest; FUIO $=$ Fear of upsetting important others.

Academic help seeking diukur menggunakan Computer Science Help Seeking Scales milik Pajares, Cheong, \& Oberman (2004) yang telah diadaptasi oleh Syafitri (2018). Alat ukur ini terdiri dari 26 item dan empat dimensi. Skala yang digunakan dalam alat ukur ini adalah skala Likert dari 1 hingga $4(1=$ sangat tidak sesuai; 2 = tidak sesuai; $3=$ sesuai; 4 = sangat sesuai). Reliabilitas alat ukur ini yaitu 0,511 untuk dimensi instrumental help seeking, 0,760 untuk dimensi executive help seeking, 0,839 untuk dimensi avoidance help seeking, dan 0,803 untuk dimensi perceived benefit of help seeking. Berdasarkan kriteria Hinton et al. (2004), alat ukur ini dapat diandalkan. Validitas alat ukur academic help seeking diperoleh melalui uji confirmatory factor analysis (CFA). Bukti validitas alat ukur academic help seeking disajikan pada Tabel 2.

Tabel 2. Validitas Alat Ukur Computer Science Help Seeking Scales

\begin{tabular}{cccc}
\hline \multirow{2}{*}{ Dimensi } & $\begin{array}{c}\text { RMSEA } \\
<0,08 \text { (Schumacker } \\
\text { \& Lomax, 2004) }\end{array}$ & $\begin{array}{c}\text { SRMR } \\
<0,08(\text { Hu \& } \\
\text { Bentler, 1999) }\end{array}$ & $\begin{array}{c}\text { CFI } \\
>0,95 \text { (Hu \& } \\
\text { Bentler, 1999) }\end{array}$ \\
\hline IHS & 0,056 & 0,035 & 0,980 \\
EHS & 0,000 & 0,011 & 1,000 \\
AHS & 0,056 & 0,046 & 0,980 \\
PBHS & 0,051 & 0,030 & 0,990 \\
\hline
\end{tabular}

Keterangan: IHS = Instrumental help seeking; EHS = Executive help seeking; AHS

= Avoidance help seeking, PBHS = Perceived benefits of help-seeking.

Pengambilan data dilakukan menggunakan metode survei dengan menyebarkan kuesioner online melalui aplikasi pengirim pesan LINE. Responden dihubungi terlebih dahulu dan diminta kesediaannya untuk berpartisipasi dalam penelitian. Responden yang bersedia kemudian dikirimkan link berisi kuesioner online yang harus diisi. Data yang diperoleh diolah menggunakan uji korelasi untuk mengetahui hubungan antara kedua variabel. 


\section{HASIL DAN PEMBAHASAN}

Mahasiswa Fakultas Psikologi Universitas Padjadjaran yang bersedia menjadi responden penelitian adalah sebanyak 185 orang yang terdiri dari angkatan 2017 (48,1\%) dan angkatan 2018 (51,9\%) dengan mayoritas responden ialah perempuan $(77,8 \%)$.

Berdasarkan Tabel 5, dapat dilihat bahwa hasil korelasi terdiri dari korelasi utama antara general fear of failure dengan dimensi academic help seeking, serta korelasi dimensi-dimensi fear of failure dengan dimensi-dimensi academic help seeking. Hasil korelasi utama menunjukkan bahwa general fear of failure memiliki hubungan positif yang signifikan dengan dimensi instrumental help seeking $\left(\mathrm{r}_{\mathrm{s}}=0,421, \mathrm{p}<0,01\right)$, executive help seeking $\left(\mathrm{r}_{\mathrm{s}}=0,211, \mathrm{p}<0,01\right)$, dan avoidance help seeking $\left(\mathrm{r}_{\mathrm{s}}=0,285, \mathrm{p}<0,01\right)$. Sementara itu, dimensi perceived benefit of help seeking tidak memiliki hubungan yang signifikan dengan general fear of failure. Hasil ini menunjukkan bahwa makin besar kekhawatiran yang dirasakan mahasiswa akan konsekuensi dari kegagalan, makin besar pula keinginan mereka untuk meminta bantuan kepada dosen berupa penjelasan maupun jawaban langsung dari suatu permasalahan akademik. Di samping itu, dapat diketahui pula bahwa makin besar kekhawatiran yang dirasakan mahasiswa akan konsekuensi dari kegagalan, makin besar pula keinginan mereka untuk menghindari meminta bantuan kepada dosen ketika mengalami kesulitan akademik.

Tabel 5. Hasil Uji Korelasi ( $\left.\mathrm{r}_{\mathrm{s}}\right)$

\begin{tabular}{ccccc}
\hline & IHS & EHS & AHS & PBHS \\
\hline GFOF & $0,421^{* *}$ & $0,211^{* *}$ & $0,285^{* *}$ & $-0,080$ \\
FESH & $0,448^{* *}$ & $0,154^{*}$ & $0,155^{*}$ & 0,024 \\
FDOS & $0,288^{* *}$ & $0,247^{* *}$ & $0,306^{* *}$ & $-0,074$ \\
FHUF & $0,238^{* *}$ & $0,232^{* *}$ & $0,197^{* *}$ & $-0,047$ \\
FIOLS & $0,506^{* *}$ & $0,165^{*}$ & $0,236^{* *}$ & 0,000 \\
FUIO & $0,389^{* *}$ & 0,050 & 0,113 & $-0,001$ \\
\hline
\end{tabular}

Keterangan: $\mathrm{N}=185 ; \mathrm{GFOF}=$ General fear of failure; $\mathrm{FESH}=$ Fear of experiencing shame and embarrassment; FDOS $=$ Fear of devaluing one's selfestimate; FHUF = Fear of having an uncertain future; FIOLS = Fear of important others losing Interest; FUIO $=$ Fear of upsetting important others; IHS = Instrumental help seeking; EHS = Executive help seeking; AHS $=$ Avoidance help seeking, PBHS $=$ Perceived benefits of help-seeking; ${ }^{*} \mathrm{p}<0,05 ; * * \mathrm{p}<$ 0,01

Kemudian, hasil korelasi antardimensi menunjukkan bahwa dimensi fear of experiencing shame and embarrassment tidak memiliki hubungan yang signifikan dengan dimensi perceived benefits of helpseeking, namun memiliki hubungan positif yang signifikan dengan tiga dimensi academic help seeking, yaitu instrumental help seeking $\left(\mathrm{r}_{\mathrm{s}}=0,448, \mathrm{p}<0,01\right)$, executive help seeking $\left(\mathrm{r}_{\mathrm{s}}=0,154, \mathrm{p}<0,05\right)$, dan avoidance help seeking $\left(\mathrm{r}_{\mathrm{s}}=0,155, \mathrm{p}<0,05\right)$. Selanjutnya, dimensi fear of devaluing one's self-estimate memiliki korelasi yang positif dengan dimensi instrumental help seeking $\left(\mathrm{r}_{\mathrm{s}}=0,288, \mathrm{p}<0,01\right)$, executive help seeking $\left(\mathrm{r}_{\mathrm{s}}=0,247, \mathrm{p}<0,01\right)$, dan avoidance help seeking $\left(\mathrm{r}_{\mathrm{s}}=0,306, \mathrm{p}<0,01\right)$.

Dimensi fear of having an uncertain future ditemukan memiliki hubungan positif signifikan dengan dimensi instrumental help seeking $\left(\mathrm{r}_{\mathrm{s}}=0,238, \mathrm{p}<0,01\right)$, executive help seeking $\left(\mathrm{r}_{\mathrm{s}}=0,232, \mathrm{p}<0,01\right)$, dan avoidance help seeking $\left(\mathrm{r}_{\mathrm{s}}=0,197, \mathrm{p}<0,01\right)$. Sementara itu, dimensi fear of important others losing interest tidak memiliki hubungan yang signifikan dengan dimensi perceived benefits of help-seeking, namun memiliki hubungan positif yang signifikan dengan instrumental help seeking $\left(\mathrm{r}_{\mathrm{s}}=0,506, \mathrm{p}<0,01\right)$, executive help seeking $\left(\mathrm{r}_{\mathrm{s}}=0,165, \mathrm{p}<0,05\right)$, dan avoidance help seeking $\left(\mathrm{r}_{\mathrm{s}}=0,236, \mathrm{p}<0,01\right)$. Sementara 
itu, dimensi fear of upsetting important others hanya memiliki hubungan positif yang signifikan dengan dimensi instrumental help seeking $\left(\mathrm{r}_{\mathrm{s}}=0,389, \mathrm{p}<0,01\right)$, sedangkan dengan ketiga dimensi lainnya, yaitu executive help seeking, avoidance help seeking, dan perceived benefit of help seeking, tidak memiliki hubungan yang signifikan.

Hasil uji korelasi menunjukkan bahwa general fear of failure memiliki hubungan positif yang signifikan dengan avoidance help seeking. Fear of failure sendiri merupakan kecenderungan seseorang untuk mengevaluasi ancaman dan merasa cemas dalam situasi yang kemungkinan menimbulkan terjadinya kegagalan (Conroy, Kaye, \& Fifer, 2007). Freud dalam Atkison (1993) menjelaskan bahwa fear of failure muncul sebagai hasil ketidakmampuan mahasiswa dalam menghadapi tuntutan akademik, yang kemudian mengakibatkan mahasiswa melakukan tindakan defensif atau pertahanan diri. Tindakan defensif mahasiswa ditunjukkan dengan menghindari meminta bantuan kepada dosen ketika mengalami kesulitan dalam hal akademik, yang disebut sebagai avoidance help seeking. Pernyataan tersebut mendukung hasil penelitian ini, di mana fear of failure diketahui memiliki hubungan positif yang signifikan dengan avoidance help seeking. Hubungan positif yang signifikan antara fear of failure dengan avoidance help seeking juga ditemukan secara dimensional, di mana dimensi fear of experiencing shame \& embarrasment, fear of devaluing one's self-estimate, fear of having an uncertain future, dan fear of important others losing interest memiliki korelasi positif dengan avoidance help seeking. Hal ini menandakan bahwa keengganan mahasiswa untuk meminta bantuan kepada dosen didasari oleh kekhawatiran akan konsekuensi dari kegagalan berupa rasa malu, penilaian buruk orang lain, ketidakpastian masa depan, serta kekecewaan dan hilangnya kepedulian orang lain.

Korelasi antara general fear of failure dengan dimensi instrumental help seeking dan executive help seeking menunjukkan hasil yang positif secara signifikan. Dimensi instrumental help seeking dan executive help seeking mengukur keinginan mahasiswa meminta bantuan terhadap dosen dalam dua jenis bantuan, yaitu meminta penjelasan dari dosen terkait suatu permasalahan untuk kemudian diselesaikan sendiri dan meminta dosen memberikan jawaban langsung terkait suatu permasalahan. Korelasi positif ini selaras dengan pernyataan Martin \& Marsh (2003), di mana berdasarkan upaya untuk mengatasinya, fear of failure dibagi menjadi dua kelompok, yaitu mahasiswa yang mengatasi fear of failure dengan aktivitas kontraproduktif sebagai upaya perlindungan diri (the self protector) dan mahasiswa yang mengatasi fear of failure dengan bekerja keras atau mencapai kesuksesan (the overstriver). Artinya, mahasiswa yang memaknai fear of failure secara negatif akan cenderung menghindari meminta bantuan kepada dosen sebagaimana yang telah dijelaskan sebelumnya, sedangkan korelasi positif yang signifikan antara general fear of failure dengan dimensi instrumental help seeking dan executive help seeking menandakan bahwa mahasiswa memaknai fear of failure sebagai sesuatu yang positif.

Korelasi antara dimensi-dimensi fear of failure dengan dimensi instrumental help seeking dan executive help seeking juga menunjukkan hasil yang positif. Dimensi tersebut di antaranya, fear of experiencing shame \& embarrasment, fear of devaluing one's self-estimate, fear of having an uncertain future, dan fear of important others losing interest. Pada dimensi fear of experiencing shame \& embarrasment, mahasiswa merasa khawatir akan mendapat penghinaan dan penilaian buruk jika tidak berhasil dalam bidang akademik di kemudian hari, sehingga mereka berusaha mengatasi hal tersebut dengan melakukan aktivitas yang meningkatkan keberhasilannya dalam bidang akademik, salah satunya dengan meminta bantuan kepada dosen ketika kesulitan memahami suatu materi. Pada dimensi fear of devaluing one's self-estimate, perasaan tidak mampu mahasiswa juga berpengaruh secara positif karena memunculkan ketertarikan terhadap suatu materi. Makin tinggi ketertarikan terhadap suatu materi, makin tinggi pula rasa ingin tahu mereka sehingga mereka akan lebih banyak meminta bantuan untuk mendapatkan pemahaman yang lebih mendalam dan memenuhi rasa ingin tahu tersebut (Bartholomé et al., 2006).

Dimensi fear of having an uncertain future dan fear of important others losing interest juga dimaknakan secara positif oleh mahasiswa, di mana rasa khawatir akan ketidakpastian di masa depan dan hilangnya kepedulian orang lain ketika mengalami kegagalan akademik membuat mahasiswa mengatasinya dengan meminta bantuan kepada dosen. Sementara itu, dimensi upsetting important others hanya memiliki hubungan dengan instrumental help seeking saja, hal ini berarti bahwa kekhawatiran akan kritikan dan rasa kecewa orang lain membuat mahasiswa merasa perlu meningkatkan keterampilan akademiknya sehingga ia meminta dosen untuk menjelaskan bagaimana cara menyelesaikan suatu persoalan yang sulit untuk kemudian ia kerjakan sendiri. Jenis bantuan yang diminta berupa penjelasan cara menyelesaikan suatu 
permasalahan, karena apabila di kemudian hari mengalami kesulitan yang sama, mahasiswa akan mampu menyelesaikannya tanpa perlu dibantu.

Selain ditemukannya hasil korelasi positif, ditemukan pula hasil yang tidak berkorelasi, yakni general fear of failure yang tidak berkorelasi secara signifikan dengan dimensi perceived benefit of help seeking. Hasil tersebut juga ditemukan secara dimensional, di mana dimensi fear of experiencing shame \& embarrasment, fear of devaluing one's self-estimate, fear of having an uncertain future, fear of important others losing interest, dan fear of upsetting important others tidak berkorelasi secara signifikan dengan perceived benefit of help seeking. Hasil ini selaras dengan pernyataan Shim, Rubenstein, \& Drapeau (2016), di mana academic help seeking pada dasarnya melibatkan psychological cost yang sering kali lebih besar dibandingkan persepsi mengenai manfaat melakukannya. Artinya, mahasiswa mungkin menyadari bahwa mereka membutuhkan bantuan, tetapi rasa khawatir akan dinilai buruk, tidak mampu, dan tidak cukup pintar oleh orang lain membuat mereka berpikir bahwa meminta bantuan hanya akan menunjukkan kekurangan diri alih-alih mendapatkan manfaat.

\section{SIMPULAN}

Berdasarkan hasil penelitian, dapat disimpulkan bahwa fear of failure berhubungan dengan academic help seeking pada beberapa dimensi, yaitu dimensi instrumental help seeking, executive help seeking dan avoidance help seeking. Hasil ini menunjukkan bahwa kekhawatiran yang dirasakan mahasiswa ketika bertanya kepada dosen dimaknakan secara positif dan negatif. Kekhawatiran yang dimaknakan secara positif diatasi mahasiswa dengan melakukan aktivitas yang mampu meningkatkan keberhasilan akademik, yakni dengan meminta bantuan dosen baik berupa penjelasan untuk kemudian diselesaikan secara mandiri, maupun jawaban langsung dari dosen. Sementara itu, kekhawatiran yang dimaknakan secara negatif diatasi mahasiswa dengan melakukan tindakan defensif, yakni dengan menghindari meminta bantuan kepada dosen. Kemudian, ditemukan pula bahwa fear of failure tidak berhubungan dengan dimensi perceived benefit of help seeking. Hal ini terjadi karena kekhawatiran yang dirasakan mahasiswa mengubah persepsi mereka mengenai manfaat meminta bantuan kepada dosen. Pada dasarnya, mahasiswa memiliki kecenderungan untuk meminta bantuan dosen, tetapi hal tersebut terkendala oleh fear of failure sehingga mayoritas dari mereka lebih memilih untuk menghindarinya.

Penelitian mengenai hubungan fear of failure dengan academic help seeking ini memiliki beberapa temuan, keterbatasan, dan kekurangan. Yang pertama, penelitian ini menggunakan sampel mahasiswa Fakultas Psikologi Universitas Padjadjaran sehingga hasil penelitian ini tidak dapat digeneralisasikan terhadap mahasiswa dengan karakteristik di luar Fakultas Psikologi Universitas Padjadjaran. Selain itu, konteks penelitian ini adalah academic help seeking terhadap dosen sehingga keinginan pencarian bantuan akademik pada penelitian ini hanya dikhususkan kaitannya dengan dosen. Oleh karena itu, dapat dilakukan penelitian lebih lanjut dengan pertimbangan di antaranya: untuk konteks situasi yang spesifik misalnya pembelajaran di mata kuliah tertentu, alat ukur fear of failure dapat dibuat lebih spesifik dalam instruksinya sehingga menghindari kemungkinan pemikiran fear of failure pada kehidupan perkuliahan secara umum. Kemudian untuk generalisasi hasil, penelitian selanjutnya terkait fear of failure dan academic help seeking dapat dilakukan terhadap kelompok mahasiswa dengan karakteristik yang berbeda.

Hasil penelitian ini dapat dimanfaatkan oleh kedua pihak, yakni mahasiswa dan dosen. Bagi mahasiswa, hasil penelitian ini dapat dimanfaatkan untuk melakukan refleksi diri terkait sejauh mana upaya mereka untuk bertanya kepada dosen, serta faktor-faktor apa yang mendukung dan menghambat mereka untuk bertanya sehingga mereka dapat menyesuaikan upaya yang tepat untuk bertanya kepada dosen dengan memperhatikan faktor pendukung dan penghambat upaya tersebut. Bagi dosen, hasil penelitian ini dapat menjadi masukan terkait penyelenggaraan kegiatan belajar mengajar yang dapat mendorong mahasiswa untuk bertanya, yakni dengan menciptakan situasi belajar yang kondusif di mana pembawaan dosen pada saat mengajar tidak terkesan intimidatif dan suasana kelas tidak terlalu ramai maupun tidak terlalu pasif. 


\section{DAFTAR PUSTAKA}

Abidin, Z. (2005). Strategi pembelajaran di perguruan tinggi (Optimalisasi kinerja dosen dalam pembelajaran di Fakultas Agama Islam Universitas Muhammadiyah Surakarta).

Altermatt, E. R., Pomerantz, E. M., Ruble, D. N., Frey, K. S., \& Greulich, F. K. (2002). Predicting changes in children's self-perceptions of academic competence: A naturalistic examination of evaluative discourse among classmates. Developmental Psychology, 38(6), 903-917.

Atkinson. (1993). Pengantar psikologi (8th ed., Jilid Dua) (Taufik, N., Dharma, A., Trans.). Jakarta: Erlangga.

Atkinson. (1957). Motivational determinants of risk-taking behavior. Psychological Review, 64, 359-372.

Bartholomé, T., Stahl, E., Pieschl, S., \& Bromme, R. (2006). What matters in help-seeking? A study of help effectiveness and learner-related factors. Review of Education Research, 22(1), 113-129.

Butler. (1998). Determinants of help seeking: Relations between perceived reasons for classroom helpavoidance and help-seeking behaviors in an experimental context. Journal of Educational Psychology, 90(4), 630-643.

Caraway, K., Tucker, C. M., Reinke, W. M., \& Hall, C. (2003). Self-efficacy, goal orientation and fear of failure as predictors of school engagement in high school students. Psychology in the Schools, 40(4), 417-427.

Christensen, L. B. (2007). Experimental methodology (10th ed.). USA: Pearson Education.

Conroy, D. E., Willow, J. P., \& Metzler, J. N. (2002). Multidimensional fear of failure measurement: The Performance Failure Appraisal Inventory. Journal of Applied Sport Psychology, 14(2), 76-90.

Conroy, D. E., Kaye, M. P., \& Fifer, A. M. (2007). Cognitive links between fear of failure and perfectionism. Journal of Rational-Emotive \& Cognitive-Behavior Therapy, 25(4), 237-253.

Elliot, A. J., \& Thrash, T. M. (2004). The intergenerational transmission of fear of failure. Personality and Social Psychology Bulletin, 30(8), 957-971.

Fatimah, O., Lukman, Z. M., Khairudin, R., Wan Shahrazad, W. S., \& Halim, F. W. (2011). Procrastination's relation with fear of failure, competence expectancy and intrinsic motivation. Pertanika Journal of Social Science and Humanities, 19, 123-127.

Hung, L., Wu, C., Hwa, Y., Lin, M., \& Shui, S. (2009). Fear of failure, 2 x 2 achievement goal and selfhandicapping: An examination of the hierarchical model of achievement motivation in physical education q. Contemporary Educational Psychology, 34(4), 298-305.

Järvelä, S. (2011). How does help seeking help? - New prospects in a variety of contexts. Learning and Instruction, 21(2), 297-299.

Kaplan, R. M. \& Saccuzzo, D. P. (2005). Psychological testing: Principles, applications, and issues. Chicago: Cengage Learning.

Kusumah, W. 2009. Murid, siswa dan mahasiswa. Retrieved from http://www.kompasiana.com/wijayalabs/murid-siswa-dan-mahasiswa_54fecc46a333118c5650f831a

Martin, A. J., \& Marsh, H. W. (2003). Fear of failure: Friend or foe? Australian Psychologist, 38(1), 3138.

Nainggolan, L. (2007). Hubungan antara persepsi terhadap harapan orang tua dengan ketakutan akan kegagalan pada mahasiswa Program Studi Psikologi Universitas Diponegoro Semarang. Universitas Diponegoro.

Newman, R. S. (2000). Social influences on the development of children's adaptive help seeking: The role of parents, teachers, and peers. Developmental Review, 20(3), 350-404.

Pajares, F., Cheong, Y. F., \& Oberman, P. (2004). Psychometric analysis of computer science help-seeking scales. Educational and Psychological Measurement, 64(3), 496-513.

Ryan, A. M., \& Pintrich, P. R. (1997). "Should I ask for help?" The role of motivation and attitudes in adolescents' help seeking in math class. Journal of Educational Psychology, 89(2), 329-341.

Ryan, A. M., Hicks, L., \& Midgley, C. (1997). Social goals, academic goals, and avoiding seeking help in the classroom. The Journal of Early Adolescence, 17(2), 152-171.

Ryan, A. M., Pintrich, P. R., \& Midgley, C. (2001). Avoiding seeking help in the classroom: Who and why? Educational Psychology Review, 13(2), 93-114.

Schumacker, R., E., \& Lomax, R., G. (2004). A beginner's guide to structural equation modeling (2nd ed.): Lawrence Eribaum Associates Publishers. 
Sebastian, I. (2013). Never be afraid hubungan antara fear of failure dan prokrastinasi akademik. Calyptra, 2(1), 1-8.

Shim, S. S., Rubenstein, L. D., \& Drapeau, C. W. (2016). When perfectionism is coupled with low achievement: The effects on academic engagement and help seeking in middle school. Learning and Individual Differences, 45, 237-244.

Syafitri, N. R. (2018). Hubungan antara efikasi diri akademik dan academic help-seeking behavior pada mahasiswa. Universitas Islam Indonesia. 